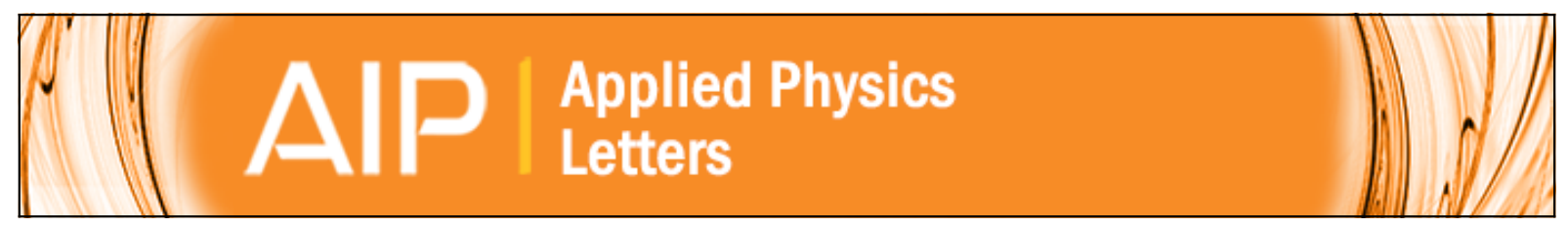

\title{
On the behavior of deuterium in ultrathin SiO 2 films upon thermal annealing
}

I. J. R. Baumvol, E. P. Gusev, F. C. Stedile, F. L. Freire Jr., M. L. Green, and D. Brasen

Citation: Applied Physics Letters 72, 450 (1998); doi: 10.1063/1.120801

View online: http://dx.doi.org/10.1063/1.120801

View Table of Contents: http://scitation.aip.org/content/aip/journal/apl/72/4?ver=pdfcov

Published by the AIP Publishing

Articles you may be interested in

Influence of $\mathrm{H} 2$-annealing on the hydrogen distribution near SiO 2 / Si (100) interfaces revealed by in situ nuclear reaction analysis

J. Appl. Phys. 92, 4320 (2002); 10.1063/1.1509084

Stability of zirconium silicate films on Si under vacuum and $\mathrm{O} 2$ annealing

Appl. Phys. Lett. 78, 2446 (2001); 10.1063/1.1367288

Annealing behavior of implanted helium in indium phosphide

Appl. Phys. Lett. 78, 207 (2001); 10.1063/1.1337643

Incorporation of oxygen and nitrogen in ultrathin films of $\mathrm{SiO} 2$ annealed in $\mathrm{NO}$

Appl. Phys. Lett. 72, 2999 (1998); 10.1063/1.121520

Back-surface passivation of polycrystalline CdSe thin-film transistors

J. Vac. Sci. Technol. A 16, 834 (1998); 10.1116/1.581068

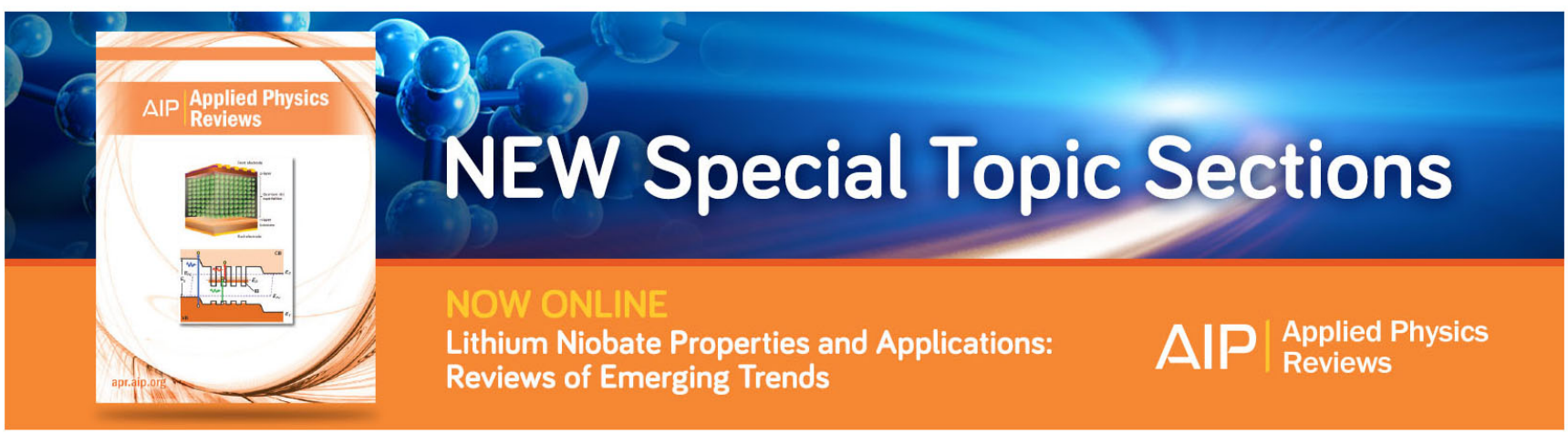




\title{
On the behavior of deuterium in ultrathin $\mathrm{SiO}_{2}$ films upon thermal annealing
}

\author{
I. J. R. Baumvol \\ Instituto de Fisica-UFRGS, Porto Alegre, RS, 91540-000, Brazil \\ E. P. Guseva) \\ Departments of Chemistry and Physics, and Laboratory for Surface Modification, Rutgers University, \\ Piscataway, New Jersey 08855 \\ F. C. Stedile \\ Instituto de Quimica-UFRGS, Porto Alegre, RS, 91540-000, Brazil \\ F. L. Freire, Jr. \\ Departamento de Física, PUC-Rio, Brasil \\ M. L. Green and D. Brasen \\ Bell Laboratories/Lucent Technologies, Murray Hill, New Jersey 07974
}

(Received 12 September 1997; accepted for publication 25 November 1997)

Following the observation of the large isotopic effect in $\mathrm{D}_{2}$ passivated gate dielectrics [J. Lyding, $\mathrm{K}$. Hess, and I. C. Kizilyalli, Appl. Phys. Lett. 68, 2526 (1996)], we studied the behavior of deuterium in ultrathin $\mathrm{SiO}_{2}$ films by nuclear reaction analysis techniques. Accurate concentrations of deuterium in the films, deuterium depth distributions, and deuterium removal from the film upon thermal annealing in vacuum have been examined. For $\mathrm{D}_{2}$ passivated films, we found rather high concentrations of deuterium near the $\mathrm{SiO}_{2} / \mathrm{Si}$ interface, well above both the solubility of deuterium in silica and the maximum concentration of electrically active defects at the interface. Our results suggest a complex multistep mechanism of thermally activated deuterium removal from the film, which probably consists of D detrapping, diffusion, and desorption steps. (C) 1998 American Institute of Physics. [S0003-6951(98)03004-6]

Recent time-dependent degradation studies ${ }^{1}$ of deuterated gate $(5.5 \mathrm{~nm})$ oxides have inspired a new wave of interest to the problem ${ }^{2-7}$ of hydrogen (and its isotope deuterium) in the $\mathrm{SiO}_{2} / \mathrm{Si}$ system. In particular, it was shown that the buildup of interface traps upon irradiation is significantly retarded in deuterium-passivated samples, and that transistor lifetime improvements (due to reduced hot-electron degradation effects) by factors of $10-50$ can be achieved. ${ }^{1}$ Subsequently, these results were reproduced by Devine et al. who showed that the lifetime for a $10 \%$ reduction in the transconductance is enhanced by $\sim 10$ times for devices annealed in $\mathrm{D}_{2}$ as compared to $\mathrm{H}_{2}{ }^{8}$ Several models have been suggested to account for this giant isotopic effect, although the behavior of deuterium in ultrathin oxides and its role in improving the properties of metal-oxide-semiconductor (MOS) devices are still not well understood. ${ }^{1,9}$

Due to its chemical similarity to hydrogen and very low background level in processing environments, it is very convenient to use deuterium as a "marker" to elucidate basic chemical and physical properties of hydrogen in $\mathrm{SiO}_{2}$ films. Previous secondary ion mass spectroscopy ${ }^{5,6,10,11}$ and nuclear reaction analysis (NRA) experiments ${ }^{3,12-15}$ made use of this fact to investigate various aspects of hydrogen in relatively thick ( $>100 \mathrm{~nm}$ ) oxide films. Ultrathin (sub-10 nm) films of interest for near-future generation of MOS devices are much less studied. In this letter, we use a highly sensitive and selective nuclear reaction analysis technique ${ }^{3,12,14,16}$ to study deuterium in ultrathin $(5.5 \mathrm{~nm}) \mathrm{SiO}_{2}$ films, specifically: (i)

${ }^{a)}$ Electronic mail: gusev@physics.rutgers.edu accurate concentrations of deuterium in the films; (ii) thermal behavior of deuterium in the oxides upon vacuum annealing; (iii) activation energies associated with deuterium removal from the film; and (iv) deuterium depth distributions. In addition to the above mentioned giant isotopic effect, ${ }^{1}$ one more practical aspect of this study follows from the fact that oxidation/annealing in $\mathrm{H}_{2}\left(\mathrm{D}_{2}\right)$ is not the final (high-temperature) processing step and it is important, therefore, to understand the response of $\mathrm{H}(\mathrm{D})$ in the film to subsequent thermal treatments.

Ultrathin $(5.5 \mathrm{~nm})$ gate oxides were grown on 6 in. $\mathrm{Si}$ (100) wafers in a vertical furnace in dry $\mathrm{O}_{2}$ at $850{ }^{\circ} \mathrm{C}$. The oxidation step was followed by annealing in $\mathrm{D}_{2}$ (diluted to $10 \%$ in an $\mathrm{N}_{2}$ buffer gas, total pressure $1 \mathrm{~atm}$ ) at $450{ }^{\circ} \mathrm{C}$ for $45 \mathrm{~min}$. The wafers were then cut into pieces, transferred (in air) to another furnace, and annealed in vacuum (2 $\times 10^{-7}$ mbar) in the temperature range of $350-600{ }^{\circ} \mathrm{C}$. Characteristic time of temperature ramp-up (cool-down) to (from) $400-600{ }^{\circ} \mathrm{C}$ was on the order of $5 \mathrm{~min}$. The concentration of deuterium was measured (with an accuracy of $\sim 5 \%$ ) by the $\mathrm{D}\left({ }^{3} \mathrm{He}, p\right){ }^{4} \mathrm{He}$ reaction at $700 \mathrm{keV}$, calibrated against a deuterated silicon nitride reference sample containing $1.55 \times 10^{17} \mathrm{D} / \mathrm{cm}^{2}$, as described in detail elsewhere. ${ }^{12,14}$ The sensitivity of this method is on the order of $10^{12} \mathrm{D} / \mathrm{cm}^{2}$. Since hydrogen (deuterium) solubility in crystalline silicon is very low, ${ }^{5}$ we consider all measured deuterium to be located in the oxide film. This was directly confirmed by depthprofiling via HF-etch back. An oxide etching rate of about $0.2 \mathrm{~nm} / \mathrm{s}$ was determined from the decay of the total amount of oxygen in the film, measured by the ${ }^{16} \mathrm{O}(\mathrm{D}, p){ }^{17} \mathrm{O}$ reaction 


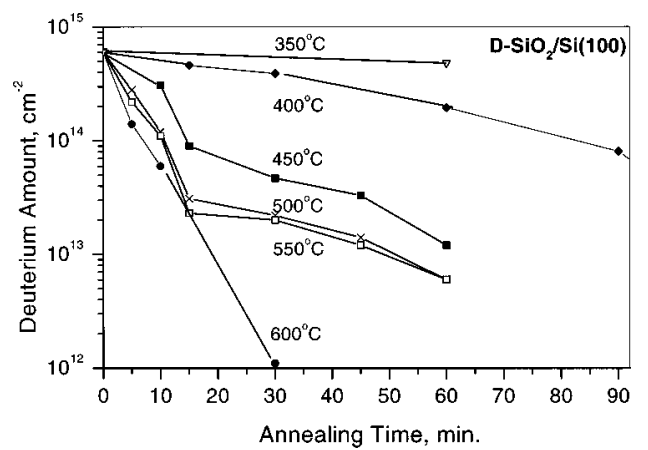

FIG. 1. Total amount of deuterium left in the $\mathrm{SiO}_{2}$ films after vacuum anneal at different temperatures. Solid lines are a guide only.

at $730 \mathrm{keV}$, with a $13 \mu \mathrm{m}$ mylar foil in front of the detector to stop deuterons, alpha particles, and low energy protons. The depth resolution of the HF etch depth profiling is estimated to be about $1 \mathrm{~nm}$.

Deuterium-annealed samples exhibit a surprisingly high concentration in the film, $6 \times 10^{14} \mathrm{D} / \mathrm{cm}^{2}$ (see Fig. 1 at $t$ $=0$ ), about three orders of magnitude higher than the "physical" solubility of molecular hydrogen (deuterium) in bulk silica in this temperature range, ${ }^{17,18} 3-4 \times 10^{17} \mathrm{at} / \mathrm{cm}^{3}$ (which corresponds to $\sim 2 \times 10^{11} \mathrm{at} / \mathrm{cm}^{2}$ for a $5.5 \mathrm{~nm}$ film). The observed amount of $\mathrm{D}$ is also much higher than the "intrinsic" level of dangling bonds at the nonpassivated $\mathrm{SiO}_{2} / \mathrm{Si}$ interface, $\sim 1 \times 10^{13} \mathrm{~cm}^{-2}$, as measured by electron paramagnetic resonance (EPR) for the $\mathrm{Si}$ (111) substrate. ${ }^{19}$ One should, however, mention that other ion-beam studies have shown that the concentration of hydrogen/deuterium at the interface of thicker $(95 \mathrm{~nm})$ silicon oxide films can be as high as $10^{15} \mathrm{at} / \mathrm{cm}^{2}$, also well above the solubility limit. ${ }^{15}$

Figure 1 shows the decay of the deuterium content in the film during vacuum anneal. One can see that the amount of $\mathrm{D}$ drops below the sensitivity limit $\left(10^{12} \mathrm{D} / \mathrm{cm}^{2}\right)$ after annealing at $600{ }^{\circ} \mathrm{C}$ for $30 \mathrm{~min}$, consistent with previous studies on deuterium removal from thicker films ${ }^{3}$ and thermal desorption experiments on deuterium absorbed on clean silicon surfaces. ${ }^{20}$ At lower temperatures $\left(T<400{ }^{\circ} \mathrm{C}\right)$, the decay is much slower. In the intermediate temperature range, the decay law becomes more complicated. A fast decay mode is observed at short annealing times ( $<15 \mathrm{~min})$, which is followed by a regime of slower decay. There is a break in the decay curves (plotted in a semilogarithmic coordinates) at $t \sim 15$ min, suggesting a complex (multistep and possibly multipath) behavior of D removal upon vacuum anneal. Each step is characterized by its decay law with a characteristic time constants $\left[\tau(T)=\tau_{0} \exp \left(E_{a} / T\right)\right]$, such that the overall decay mechanism could be described as $C_{D}(t)=C_{1}(0)$ $\times \exp \left[-t / \tau_{1}(T)\right]+C_{2}(0) \exp \left[-t / \tau_{2}(T)\right]+\ldots$

The time constant $\left(\tau_{1}\right)$ for the fast decay mode (determined from the least-squares fit of the slope of the straight lines in Fig. 1 at $t<15 \mathrm{~min}$ ) is shown as a function of the inverse temperature in Fig. 2. This Arrhenius plot allows one to obtain apparent activation energies $\left(E_{a}\right)$, associated with deuterium removal from the film upon annealing. They are $\sim 0.35 \mathrm{eV}$ for $T>450{ }^{\circ} \mathrm{C}$, and $\sim 1.2 \mathrm{eV}$ for lower temperatures. Again, these results imply a multistep removal mechanism: At lower temperatures, the process with the higher activation energy is rate limiting, whereas the process with

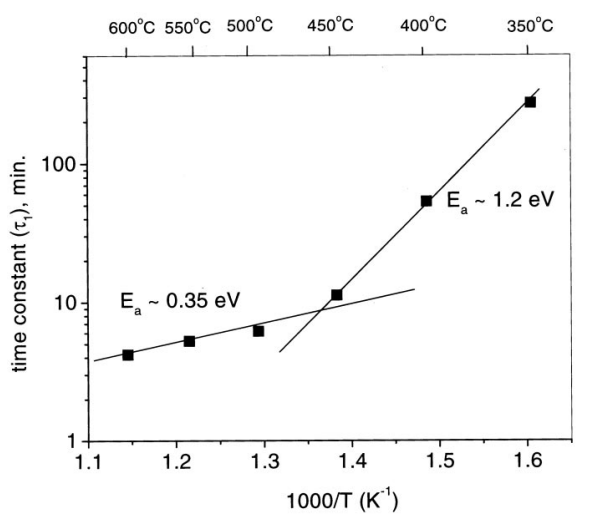

FIG. 2. Time constant $\left(\tau_{1}\right)$ of the fast $(t<15 \mathrm{~min})$ stage of deuterium removal from the films as a function of inverse temperature.

the lower activation energy governs D removal at higher temperatures.

The depth distributions of deuterium in the initial deuterated oxide ( $t=0$ in Fig. 1) and at an intermediate step of vacuum anneal $\left(450{ }^{\circ} \mathrm{C}\right.$ for $\left.30 \mathrm{~min}\right)$ are shown in Fig. 3. The initial deuterated film has $6 \times 10^{14} \mathrm{D} / \mathrm{cm}^{2}$ located closer to the $\mathrm{SiO}_{2} / \mathrm{Si}$ interface. This result is complementary to recent observations by Devine et al. ${ }^{8}$ who showed by charge pumping techniques that the improved properties of deuterated oxides can be attributed to interface state passivation by deuterium. After vacuum anneal, the distribution is quite different: (i) the total amount of the isotope decreases by more than one order of magnitude, a result of D removal from the film; and (ii) the distribution exhibits two peaks-one near the interface and a new one near the surface of the oxide. For this set of particular annealing conditions $\left(450{ }^{\circ} \mathrm{C}, 30 \mathrm{~min}\right)$, the deuterium is almost equally distributed in the two regions: $2.6 \times 10^{13} \mathrm{D} / \mathrm{cm}^{2}$ near the outer oxide surface and 2 $\times 10^{13} \mathrm{D} / \mathrm{cm}^{2}$ near the interface. Deuterium fixation near the surface implies the existence of either specific bounded configurations of D near/at the surface (such as, for example
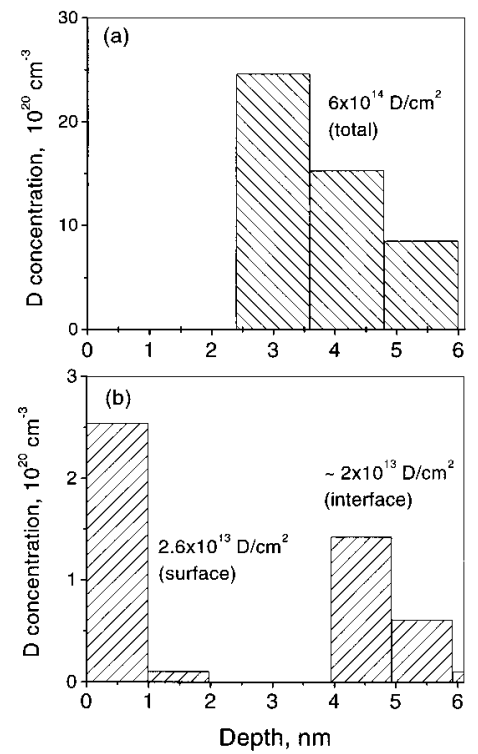

FIG. 3. Deuterium depth profiles (as a function of the distance from the outer oxide surface) for (a) the initial deuterated film before vacuum anneal and (b) after intermediate vacuum anneal at $450{ }^{\circ} \mathrm{C}$ for $30 \mathrm{~min}$. 
$\mathrm{Si}-\mathrm{OD}$ and $\mathrm{Si}-\mathrm{D}$ groups, some of them could be caused by $\mathrm{H} / \mathrm{D}$ exchange at the surface) or/and an energy barrier for D to desorb into the vacuum. The thermally activated nature of deuterium desorption was indeed observed in thermal desorption experiments of deuterium on clean Si surfaces ${ }^{20}$ and in $\mathrm{D}_{2} \mathrm{O}$ grown films. ${ }^{21}$ One should note that, after this intermediate vacuum annealing, the amount of deuterium near the interface $\left(2 \times 10^{13} \mathrm{D} / \mathrm{cm}^{2}\right)$ approaches the intrinsic level of the interface traps $\left(1 \times 10^{13} \mathrm{D} / \mathrm{cm}^{2}\right)^{19}$ which may indicate that this relatively strongly bonded deuterium is responsible for the passivation of the interface defects.

The activation energy of $0.35 \mathrm{eV}$ for the fast initial decay at $T>450{ }^{\circ} \mathrm{C}$ (Fig. 2) agrees with the activation energy of molecular deuterium (hydrogen) diffusion in silica of $E_{d}$ $\sim 0.38 \mathrm{eV} .^{18}$ (Park et al. reported a different value of $E_{d}$ $=1.9 \mathrm{eV}$ for diffusion of implanted deuterium in "wet" oxides. ${ }^{5}$ One should, however, keep in mind that hydrogen/ deuterium diffusivity in silica is very sensitive to the "dryness" of the oxide. ${ }^{7}$ ) As far as the value of $1.25 \mathrm{eV}$ (Fig. 2) at $T<450{ }^{\circ} \mathrm{C}$ is concerned, at the moment, we cannot identify a known process involving $\mathrm{D}$ in $\mathrm{SiO}_{2}$ with this activation energy. It is about half of the $\mathrm{Si}-\mathrm{D}$ surface bond strength of $2.67 \mathrm{eV}$ (Ref. 22) and the activation energy for dissociation of deuterium-passivated interface defects $\left(P_{b}\right)$ of $2.56 \mathrm{eV},{ }^{4}$ and higher than the activation energies of $\mathrm{H}_{2} \mathrm{O}$ and $\mathrm{OH}$ diffusion in $\mathrm{SiO}_{2}, 0.86$ and $0.8 \mathrm{eV}$, respectively. ${ }^{23-25}$ It may reflect the activation energy for deuterium desorption from the oxide surface or it may be indicative of the multiple dissociation, diffusion, and reaction steps that yield an apparent activation energy quite different from activation energies of the individual steps involved.

Based on our results (specifically: (i) high concentration of D in the film [Figs. 1 and 3(a)], (ii) D depth distributions (Fig. 3), (iii) multistep features observed in the $t$, and $T$ dependences (Figs. 1 and 2)) one can speculate on D behavior in the following way. During $\mathrm{D}_{2}$ annealing, deuterium both passivates the interface defects and incorporates in the nearinterface oxide. Hydrogen (deuterium) passivation of the interface traps is fairly well understood. ${ }^{4,7,8,19,26,27}$ It is also known that protons can exist in the $\mathrm{SiO}_{2}$ in several forms, such as hydroxyl and hydride groups, molecular hydrogen, etc. The high concentration of $\mathrm{D}$ near the interface may be caused (in addition to the dangling bond passivation) by deuterium bonding to other (electrically nonactive) defects in the structural transition region (including strain, suboxide states, etc.) near the interface.

Vacuum annealing results in fast (possibly diffusionlimited at high temperatures) removal of deuterium from the "bulk" near-interface oxide and slower depassivation of the interface defects. Based on the rate constant determined from the EPR measurements ${ }^{4} \quad\left[k_{\mathrm{epr}}=9.8\right.$ $\left.\times 10^{11} \exp (-2.56 \mathrm{eV} / \mathrm{kT}) \mathrm{s}^{-1}\right]$ for depassivation of the dangling bonds in a deuterated $(50 \mathrm{~nm})$ oxide, one can estimate that the time constant $\left[\tau_{\text {epr }}(T)=1 / k_{\text {epr }}\right]$ for D removal from the dangling bonds ranges from $5.5 \mathrm{~min}\left(\right.$ at $600{ }^{\circ} \mathrm{C}$ ) to 1.1 $\times 10^{5} \mathrm{~min}\left(\right.$ at $\left.400{ }^{\circ} \mathrm{C}\right)$. The time constant deduced from our experiment (Fig. 2) is $4.2 \mathrm{~min}$ at $600{ }^{\circ} \mathrm{C}$ and $45 \mathrm{~min}$ at $400{ }^{\circ} \mathrm{C}$. Comparison of the two time constants (from $\mathrm{EPR}^{4}$ and NRA, this work) suggests that, at low temperatures, deuterium atoms, passivating the interface traps, are relatively stable and the deuterium is more favorably removed from other configurations in the near-interface oxide. As the temperatures increase, the rate of depassivation of the dangling bonds also becomes high, and as a result, fast decay of deuterium to below the detection limit is observed (Fig. 1).

The authors would like to thank E. Poindexter, E. Garfunkel, J. J. Ganem, C. Radtke, and L. Feldman for discussions. E.G. acknowledges partial support from NSF (ECS9530984) and SRC/Lucent (97-BJ-451).

${ }^{1}$ J. M. Lyding, K. Hess, and I. C. Kizilyalli, Appl. Phys. Lett. 68, 2526 (1996).

${ }^{2}$ N. S. Saks and R. W. Rendell, IEEE Trans. Nucl. Sci. 39, 2220 (1992).

${ }^{3}$ S. M. Myers, J. Appl. Phys. 61, 5428 (1987).

${ }^{4}$ K. L. Brower, Phys. Rev. B 42, 3444 (1990).

${ }^{5}$ H. Park and C. R. Helms, J. Electrochem. Soc. 139, 2042 (1992).

${ }^{6}$ H. Fukuda, T. Ueno, H. Kawarada, and I. Ohdomari, Jpn. J. Appl. Phys., Part 2 32, L569 (1993).

${ }^{7}$ E. H. Poindexter, G. J. Gerardi, and D. J. Keeble, The Physics and Chemistry of $\mathrm{SiO}_{2}$ and the $\mathrm{Si}-\mathrm{SiO}_{2}$ Interface-3, edited by H. Z. Massoud, $\mathrm{E}$. H. Poindexter, and C. R. Helms (The Electrochemical Society, Pennington, NJ, 1996), p. 172.; E. H. Poindexter, C. F. Young, and G. J. Gerardi, Fundamental Aspects of Ultrathin Dielectrics on Si-based Devices, edited by E. Garfunkel, E. P. Gusev, and A. Y. Vul' (Kluwer, Dordrecht/Boston/ London, 1998), p. 397.

${ }^{8}$ R. A. B. Devine, J.-L. Autran, W. L. Warren, K. L. Vanheusdan, and J.-C. Rostaing, Appl. Phys. Lett. 70, 2999 (1997).

${ }^{9}$ C. G. Van de Valle and W. B. Jackson, Appl. Phys. Lett. 69, 2441 (1996).

${ }^{10}$ N. M. Johnson, D. K. Biegelsen, M. D. Moyer, V. R. Deline, and J. C. A. Evans, Appl. Phys. Lett. 38, 995 (1981).

${ }^{11}$ R. Gale, H. Chew, F. J. Feigl, and C. W. Magee, The Physics and Chemistry of $\mathrm{SiO}_{2}$ and the $\mathrm{Si}-\mathrm{SiO}_{2}$ Interface, edited by C. R. Helms and $\mathrm{B}$. E. Deal (Plenum, New York, 1988), p. 177.

${ }^{12}$ I. J. R. Baumvol and C. Rolfs, Nucl. Instrum. Methods Phys. Res. B 99, 431 (1995).

${ }^{13}$ Q. Qiu, E. Arai, and Y. Ohji, Nucl. Instrum. Methods Phys. Res. B 56/57, 816 (1991).

${ }^{14}$ I. J. R. Baumvol, F. C. Stedile, J. J. Ganem, I. Trimaille, and S. Rigo, J. Electrochem. Soc. 143, 1426 (1996).

${ }^{15} \mathrm{~J}$. Krauser, A. Weidinger, and D. Braunig, The Physics and Chemistry of $\mathrm{SiO}_{2}$ and the Si-SiO2 Interface-3, edited by H. Z. Massoud, E. H. Poindexter, and C. R. Helms (The Electrochemical Society, Pennington, NJ, 1996), p. 184.

${ }^{16}$ Q. Qiu, E. Arai, M. Aratani, M. Yanokura, T. Nozaki, Y. Phji, and R. Imura, Nucl. Instrum. Methods Phys. Res. B 44, 179 (1989).

${ }^{17}$ J. F. Shackelford, P. L. Studt, and R. M. Fulrath, J. Appl. Phys. 43, 1619 (1972).

${ }^{18}$ J. E. Shelby, J. Appl. Phys. 48, 3387 (1977).

${ }^{19}$ A. Stesmans and G. Van Gorp, Appl. Phys. Lett. 57, 2663 (1990).

${ }^{20}$ M. Suemitsu, H. Nakazawa, and N. Miyamoto, Appl. Surf. Sci. 82/83, 449 (1994).

${ }^{21}$ K. Muraoka, S. Takagi, and A. Toriumi, Extended Abstract of the 1996 International Conference on Solid State Devices and Materials (unpublished), p. 500

${ }^{22}$ W. R. Wampler, S. M. Myers, and D. M. Follstaedt, Phys. Rev. B 48, 4492 (1993).

${ }^{23}$ D. L. Griscom, J. Appl. Phys. 58, 2524 (1985).

${ }^{24}$ R. A. B. Devine and C. Fiori, J. Appl. Phys. 58, 3368 (1985).

${ }^{25}$ A. J. Moulson and J. P. Roberts, Trans. Faraday Soc. 57, 1208 (1961).

${ }^{26}$ J. H. Stathis, D. A. Buchanan, D. L. Quinlan, A. H. Parsons, and D. E. Kotecki, Appl. Phys. Lett. 62, 2682 (1993).

${ }^{27}$ E. Cartier and D. J. DiMaria, Microelectron. Eng. 22, 207 (1993). 